\title{
ASTER Observations of the Spectral Emissivity for Arid Lands
}

\author{
Thomas Schmugge, Andrew French, Jerry Ritchie, Mark Chopping and Al Rango \\ USDA Hydrology Lab, Beltsville, MD 20705, USA \\ Tel:301-504-8554, FAX:301-504-8931, email: schmugge@hydrolab.arsusda.gov
}

\begin{abstract}
On May 9, 2000 the Advanced Spaceborne Thermal Emission and Reflection radiometer (ASTER) on the Terra satellite obtained data over the Jornada Experimental Range test site along the Rio Grande river and the White Sand National Monument in New Mexico. ASTER has 14 channels from the visible (VNIR) through the thermal infrared (TIR) with $15 \mathrm{~m}$ resolution in the VNIR and $90 \mathrm{~m}$ in the TIR. The overpass time is approximately $11 \mathrm{AM}$. With 5 channels between 8 and $12 \mu \mathrm{m}$ these multispectral TIR data from ASTER provide the opportunity to separate the temperature and emissivity effects observed in the thermal emission from the land surface. Ground measurements during these overflights included surface temperature, vegetation type and condition and limited surface emissivity measurements. There was also an aircraft flight with the MODIS/ASTER simulator on June 14, 2000, unfortunately not coincident with a satellite overpass. Preliminary results indicate good agreement between ASTER brightness temperatures and ground measures. Analysis of earlier aircraft data has shown that the multispectral TIR data are very effective for estimating both the surface temperature and emissivity. These results will be compared with those obtained from the ASTER data for this site. With multispectral thermal infrared observations provided by ASTER it is possible for the first time to estimate the spectral emissivity variation for these surfaces on a global basis at high spatial resolution.
\end{abstract}

\section{INTRODUCTION}

Knowledge of the surface emissivity is important for determining the radiation balance at the land surface. For heavily vegetated surfaces there is little problem since the emissivity is relatively uniform and close to one. However, for arid lands with sparse vegetation the problem is difficult because the emissivity of the exposed soils and rocks is highly variable. This is shown in Fig. 1 where laboratory measurements of emissivity for several relevant soils are presented. In particular note the strong variations of emissivity in the 8 to $9 \mu \mathrm{m}$ region. The data we will present are early ASTER data acquired over the Jornada Experimental Range and the White Sand National Monument in New Mexico on May 09, 2000. The Jornada site is typical of a desert grassland where the main vegetation components are grass and shrubs.

The thermally emitted radiance from any surface depends on two factors: 1) the surface temperature, which is an indication of the equilibrium thermodynamic state resulting from the energy balance of the fluxes between the atmosphere, surface and the subsurface soil; and 2) the surface emissivity which is the efficiency of the surface for transmitting the radiant energy generated in the soil into the atmosphere. The latter depends on the composition, surface roughness, and physical parameters of the of surface, e.g. moisture content. In addition, the emissivity generally will vary with wavelength for natural surfaces. Thus to make a quantitative estimate of the surface temperature we need to separate the effects of temperature and emissivity in the observed radiation. The Temperature Emissivity Separation (TES) algorithm is used to extract the temperature and 5 emissivities from the 5 channels of ASTER

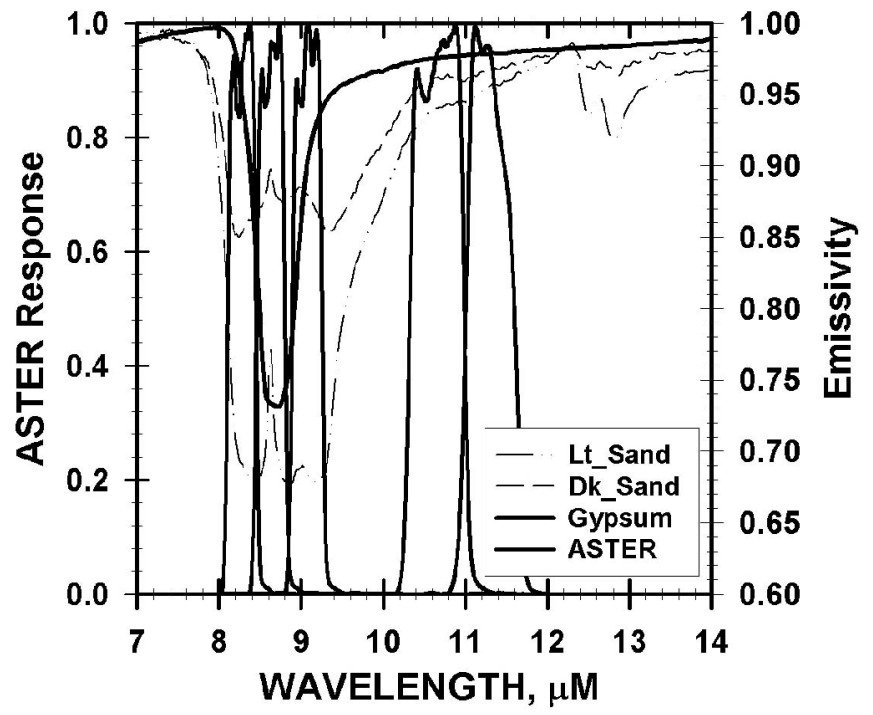

Fig. 1. Plots of spectral emissivity variation for 3 soils from New Mexico and the response functions for the 5 ASTER thermal infrared channels. Note that the emissivity curve for the light sand is the one that goes below 0.70 .

data. TES makes use of an empirical relation between the range of observed emissivities and their minimum value. This approach will be demonstrated with data acquired over the Jornada Experimental Range in New Mexico.

\section{JORNADA SITE}

The Jornada Experimental Range lies between the Rio Grande flood plain (elevation $1190 \mathrm{~m}$ ) on the west and the crest 
of the San Andres mountains $(2830 \mathrm{~m})$ on the east. The Jornada is $783 \mathrm{~km}^{2}$ in area and is located $37 \mathrm{~km}$ north of Las Cruces, New Mexico on the Jornada del Muerto Plain in the northern part of the Chihuahuan Desert. The larger Jornada del Muerto basin is typical of the Basin and Range physiographic province of the American Southwest and the Chihuahuan Desert [1].

Three specific sites in the Jornada were chosen for intensive studies. Sites were selected to represent grass, shrub (mesquite), and grass-shrub transition areas. The grass site is in a fairly level area where black grama dominates and encompasses an exclosure where grazing has been excluded since 1969. Honey mesquite on coppice dunes dominates the shrub site. The dunes vary in height from 1 to $4 \mathrm{~m}$ with honey mesquite bushes on each dune. Bare soil dominates the lower areas between these coppice dunes with most of this area covered by a darker soil with a consolidated crust. However a portion of the interdunal area is covered by a bright quartz rich sand. Samples of these two soils were taken to the Jet Propulsion Laboratory for measurements of their emissivity spectra. The results are shown in Fig. 1 along with the ASTER spectral response functions and the emissivity spectra for the gypsum sand from the White Sands area. It is clear that there will be a variation of the emissivity for the 5 ASTER channels for these soils with the longer wavelength ones $(8<\lambda<9.5 \mu \mathrm{m})$ having noticeably lower emissivities.

\section{ASTER}

ASTER [2] has 5 thermal infrared channels between 8 and $12 \mu \mathrm{m}$ as seen in Fig. 1. The central wavelengths of the channels are: $8.29,8.63,9.08,10.66$ and $11.29 \mu \mathrm{m}$. These channels have a spatial resolution of $90 \mathrm{~m}$. The data we present were acquired at 18:12 GMT or 11:12 MST on May 09, 2000. The scene is cloud free and covers the Jornada site in the southwest corner and White Sands about $50 \mathrm{~km}$ to the northeast.

The radiance at the satellite is given by

$$
\mathrm{L}_{\mathrm{j}}(\operatorname{surf})=\left(\mathrm{L}_{\mathrm{j}}(\mathrm{a} / \mathrm{c})-\mathrm{L}_{\mathrm{j}}(\operatorname{atm} \uparrow)\right) / \tau_{\mathrm{j}}
$$

where the values of $\tau_{j}$ and $L_{j}(\operatorname{atm} \uparrow)$ can be calculated using an atmospheric radiative transfer model, e.g. MODTRAN-4, with nearby radiosonde data. The latter were obtained from the 00 GMT NOAA sounding at El Paso. The profile was adjusted for the surface temperature and humidity conditions. The remaining problem is to relate these radiances to the surface emissivity in the 5 channels without direct knowledge of the temperature, $\mathrm{T}_{\mathrm{grd}}$ using the relation:

$$
\mathrm{L}_{\mathrm{j}}(\operatorname{surf})=\epsilon_{\mathrm{j}} \mathrm{BB}_{\mathrm{j}}\left(\mathrm{T}_{\mathrm{grd}}\right)+\left(1-\epsilon_{\mathrm{j}}\right) \cdot \mathrm{L}_{\mathrm{j}}(\mathrm{atm} \downarrow)
$$

where $\mathrm{BB}(\mathrm{T})$ is the Planck equation for the radiation from a black body.

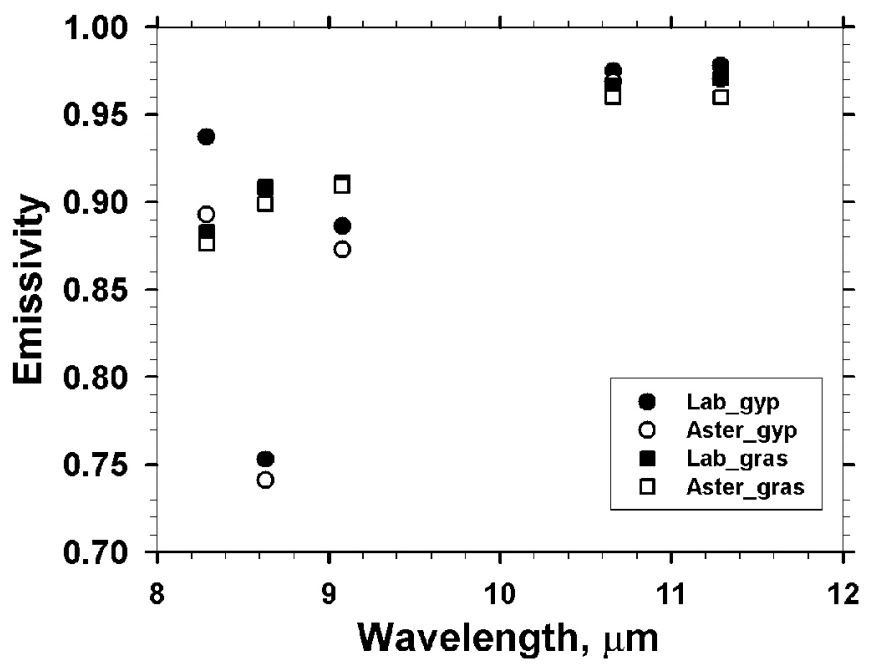

Fig. 2. ASTER emissivity results for a gypsum site at White Sands and the grass site at the Jornada. The open symbols are the ASTER results and the closed are the lab results.

Equation 2 indicates that if the radiance is measured in $n$ spectral channels, there will be $n+1$ unknowns: $n$ emissivities and the unknown surface temperature. The equations described by a set of radiance measurements in $n$ spectral channels is thus under determined, and additional information is needed in order to extract the temperature and emissivity information. Using an empirical relation between $\epsilon_{\min }$ and $\Delta \epsilon$, Gillespie et al. [3] developed the Temperature Emissivity Separation (TES) algorithm for use with ASTER data. The approach has been successfully demonstrated with data from multispectral thermal infrared data from aircraft platforms in HAPEX-Sahel[4] and for this site [5].

\section{RESULTS AND CONCLUSIONS}

The radiances for a 2 by 2 pixel area ( $\sim 180$ by $180 \mathrm{~m}$ ) from White Sands were analyzed and the results are presented in Fig. 2 , filled and open circles. The ASTER results show excellent agreement with the laboratory results. The latter were obtained for each ASTER channel by integrating the product of the ASTER response and gypsum emissivity curve shown in Fig. 1. The agreement is particularly clear for the low emissivity 8.6 $\mu \mathrm{m}$ channel.

Also shown in Fig. 2 are results for a 2 by 2 pixel area from the grass site at the Jornada, the filled and open squares. Again the agreement between the ASTER results and those calculated from the lab spectra is very good. This is a little surprising because there is generally a mix of bare soil and sensecent vegetation at this site so that we would have expected to see a flatter spectral response due to the vegetation. Another interesting result is the lack of variation $(<0.01)$ between the two sites for the long wavelength channels. 


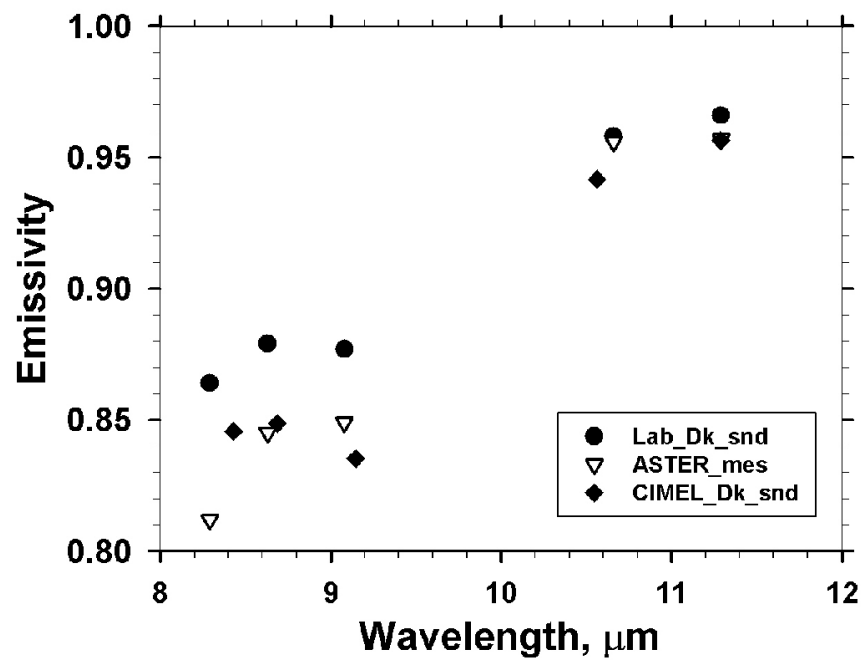

Fig. 3. ASTER emissivity results for the mesquite site, again the open symbols represent the ASTER results.

The results for the mesquite site are given in Fig. 3. In this case there is larger difference between the lab results and the ASTER results, e.g. 0.05 for the $8.29 \mu \mathrm{m}$ channel. At this site we made field measurements with a CIMEL 312 [6] radiometer which has approximately the same 5 spectral bands as ASTER. The CIMEL results also disagree with the lab calculations and we suspect that this may be due to the fact the lab measurements were made on a powdered sample of the soil while the field measurements were done on the consolidated surface. The other surprising thing is that the effects of the light sand with its low emissivity at $8-9 \mu \mathrm{m}$ and the vegetation of the mesquite bushes are not apparent.

These results indicate that the TES algorithm appears to work as well with the data from space as it did with the aircraft data presented earlier [4],[5]. This is encouraging for the application of the technique for mapping emissivity over large areas.

\section{ACKNOWLEDGMENT}

This research was supported by the ASTER project of NASA's EOS-Terra program. The laboratory emissivity measurements were made by Cindy Grove of the Jet Propulsion Laboratory.

\section{REFERENCES}

[1] K.M. Havstad, W.P. Kustas, A. Rango, J. Ritchie, and T.J. Schmugge, "JORNADA EXPERIMENTAL RANGE: A Unique location for remote sensing experiments to validate EOS satellite systems and to understand the effects of climate change in arid environments," Remote Sensing of Environment, 74 (1), pp. 13 - 25, 2000.
[2] Y. Yamaguchi, A. B. Kahle, H. Tsu, T. Kawakami, and M. Pniel, "Overview of Advanced Spaceborne Thermal Emission and Reflection Radiometer (ASTER)," IEEE Transactions on Geoscience and Remote Sensing, 36, pp. 1062-1071, 1998.

[3] A. Gillespie, S. Rokugawa, T. Matsunaga, J. S. Cothern, S. Hook, and A. B. Kahle, "A temperature and emissivity separation algorithm for Advanced Spaceborne Thermal Emission and Reflection Radiometer (ASTER) images," IEEE Transactions on Geoscience and Remote Sensing, 36, pp. 1113-1126, 1998.

[4] T.J. Schmugge, S.J. Hook, and C. Coll, "Recovering surface temperature and emissivity from thermal infrared multispectral data," Remote Sensing of Environment., 65, pp. 121-131, 1998.

[5] T. Schmugge, A. French, J.C. Ritchie, A. Rango, and H.Pelgrum, "Temperature and emissivity separation from multispectral thermal infrared observations.," Remote Sensing of Environment, In press, 2001.

[6] M. Legrand, C. Pietras, G. Brogniez, M. Haeffelin, N.K. Abuhassan and M. Sicard, "A High-accuracy multiwavelength radiometer for in situ measurements in the thermal infrared. Part 1: Characterization of the instrument," Journal of Atmospheric \& Oceanic Technology, 71, pp. 1203-1214, 2000. 